next to the text in what is normally the margin, making great use of space. This alone is a great improvement.

Peru has about 1800 species or one fifth of the world's birds. Most sources cite this vague number. The few that are more precise give numbers that vary by up to 100 species. It is not surprising that a state of flux exists in such a vast and complex area. This book covers 1792 species which is probably as good as you do under such fluctuating circumstances. Trying to reconcile the list of species covered by both books or given in other sources is very difficult. It is a bit like trying to compile a list of "honest" politicians. The new book drops some questionable records like Plumbeous Ibis [one old, suspect, badly labeled specimen] but adds Bogota Rail [based on a current valid sighting.] Some birds are treated by Shulenburg as sub-species; Andean Ibis is listed as a sub-species of Black-faced Ibis whereas other sources give it full species status. There are complications due to name changes. For example, there are four toucans listed in both books. However, the names do not correlate well. This includes the scientific binomials, normally a very stable source of information. The old book has Toco Toucan Ramphastos toco, Black-mandibled Toucan Ramphastos ambigus Yellow-ridged Toucan Ramphastos culminates, and Cuvier's Toucan Ramphastos cuvieri. The new book has Toco Toucan Ramphastos toco, Black-mandibled Toucan Ramphastos ambigus plus White-throated Toucan Ramphastos tucanus, and Channel-billed Toucan Ramphastos vitellinus. The last two are new names for Cuvier's and Yellow-ridged Toucans. [Speciation in the whole toucan complex is confused.] I also noted that Andean Flamingo and James's [Puna] Flamingo have been updated to Phoenicoparrus andinus and Phoenicoparrus jamesi, respectively, but the Guanay and Red-legged Cormorants

\section{The Freshwater Fishes of British Columbia}

By J. D. McPhail, illustrated by D. L. McPhail, foreword by Joseph S. Nelson. 2007. University of Alberta Press, Edmonton. 1 xxiv +620 pages. $\$ 90.00$.

This book is the latest treatment covering the freshwater fishes of British Columbia. Earlier books appeared in 1948 (132 pages) and 1967 (192 pages). They were published by the British Columbia Provincial Museum (now Royal British Columbia Museum) while the latest book is published, strangely, in Alberta. The present volume is 694 pages long with a larger format and is indicative of both the growth in knowledge and the need for a comprehensive work on this provincial fauna.

The book is composed of introductory sections covering purpose, use of keys, names of fishes, layout of the book, origins of the fauna, present distributions, and conservation. The sections on glacial events and have not been changed to Leucocarbo bougainvillii and Leucocarbo gaimardi. So those with a penchant for lists may need to do some research. That being said, this book is more than adequate as a field guide for the resident and visiting birder alike.

The color plates are opposite the descriptions and distribution maps. There are 13 illustrators, so there is some difference in style. The most disparate are Laurence McQueen and John O'Neill. O'Neill's work has the precise, almost photographic rendering we see in most modern field guides. McQueen's paintings are more flowing and look like paintings. My junior school art teacher would have said they were more "painterly." Daniel Lane's work is somewhat in between these two styles. Which style you like is a matter of taste. I have looked at many of the illustrations for accuracy and can find no problems. In fact, I particularly like the toucanets by O'Neill and the jaegers by McQueen. There are 4000 color illustrations at about six to a plate, meaning the illustrations are quite large [again the publisher has used the margins].

In addition to the species accounts there are wellwritten sections on Habitats, Molts-and-Plumages, and Conservation. In particular the terminology used for habitat in the species accounts is clearly documented. The text in the species accounts covers the key identification features, status, distribution, and song.

This book will please birders and biologists living in or visiting Peru. It is also useful beyond the borders of Peru into adjacent areas of South America. It is a little on the heavy side for dragging through a hot jungle, but what else can you expect with such an enormous bird list.

ROY JOHN

2193 Emard Crescent, Ottawa, Ontario K1J 6K5 Canada

current distributions are a very useful synthesis as is the discussion on what a species is and why the various forms of sticklebacks and others have not been named taxonomically.

The bulk of the text is the descriptions of species. Family accounts give general information on the included species and the identification keys are found there. The species accounts are preceded by a pictorial key to families that works for the more distinctive body shapes but would have benefited from some annotations for those fish that are more similar in shape to enable the naïve reader to correctly identify the family. It is always a debate as to whether keys should be with the family or should form a separate section. The former works when reading through the book but the latter is much easier for the actual identification process in a laboratory or the field. The keys are well illustrated al- 
though both illustrations and text are too small. Particularly useful are keys to fry, parr, and adult salmons and trouts as these life history stages differ in appearance.

Each species account has a scientific name (but no date with the author), English common name, a blackand-white illustration, sections on distinguishing features, taxonomy, sexual dimorphism, hybridization, distribution with a spot map, life history, reproduction, age, growth and maturity, food habits, habitat and conservation comments.

A total of 81 species are covered, including 10 exotics. The main families of the 17 known from British Columbia are salmons, trouts and whitefishes with 23 species, minnows (20), and sculpins (8). Minor errors are inevitable in any work; e.g., Lindsey is misspelled in the dedication, Qadri as Quadri in the References, but some can be confusing; e.g., on page 498 Pomoxis nigromaculatus is said to have 5 anal spines in the sunfish identification key but most fish have 67 spines; the stickleback key separates two species by non-overlapping dorsal fin spine counts (which do, however, overlap occasionally) where in one species (Pungitius) the spines are staggered left to right, an easily seen and unique character (mentioned in Distinguishing Characters).

The book ends with an extensive Bibliography, an Appendix I (a checklist of the fishes, with no other appendices), a Glossary and an index to scientific and common names. The Glossary explains a variety of terms, even that the plural of dentary is dentaries which is fairly standard English, but gives axillae without explaining it is the plural of axilla (a knowledge of Latin is ever more dead). One obscure word is snye, defined as a dead-end side channel. This is listed in dictionaries as an Ontario word and can also mean a channel joining two rivers.

Cost is increasingly a factor in production of books and this may explain the absence of any colour plates.

\section{Owls of the World}

By J. Duncan. 2003. Key Porter Books, Toronto, Ontario. 319 pages. Hardcover, $\$ 60$.

This beautiful book actually fulfills the two roles that many natural history books aspire to but usually fall short of ... being both a detailed scientific reference and easy to read. The first two-thirds of the book cover the biology and life history of owls, stories by people who have uncovered these amazing details and the methods they used, the substantial role that owls have in mythology around the world, and threats to their survival (but also the passion and hope that people hold out for owls). The U.S. edition, published by Firefly Books, carries the apt subtitle "their lives, behaviour and survival".

The last third of the book is a detailed look at 205 species of owls: physical description, habitat, natural history, general distribution and their global conserva-
In my mind this argues for including a CD/DVD with the book to carry photographs of habitats and coloured depictions of fishes. The text can also be put on the disk, making the book searchable. I still prefer a book in the hand to a computer screen but suspect this does not apply to a younger generation. Even the $\mathrm{CD}$ in a pocket at the back of the book is a transitional stage and "books" should now appear on the internet, thereby saving trees, allowing a plethora of colour plates and other illustrations, enabling the author to receive and incorporate feedback and new data, and facilitating correction of errors of fact and of omission. A "book" on a website can be built up incrementally although some will inevitably fail to reach a completed form. Each stage allows for criticism and correction, from the initial checklist of species, the identification keys, distribution maps (allowing zoom-in for finer details than part of a book page allows), and finally text descriptions.

For those worried about vanishing websites, EM pulses and cyber trashing, a printout of say 20 copies of the digital "book" can be deposited in various libraries. This trend can be seen in some scientific works such as the "Annotated Checklists of Fishes" produced by the California Academy of Sciences which are on-line at that institution but have copies deposited in a minimum of six natural history institutions worldwide, admittedly as CDs.

This is the definitive book on this fish fauna and an essential tome for any student of the aquatic environment in British Columbia. Future versions will require multiple authors to match and improve on the experience and knowledge exhibited here by Don McPhail.

BRIAN W. COAD

Canadian Museum of Nature, P.O. Box 3443, Station D, Ottawa, Ontario K1P 6P4 Canada

tion status. Even a quick look highlights how difficult it is to study some of these species, as many do not have photographs.

Duncan brings not only his own wealth of knowledge and field experience (particularly with Great Gray Owls) to this task, but also those of a "whoo's whoo" in the world of owls, such as Robert W. Nero, Irina Menyushina, C. Stuart Houston, and Aki Higuchi. Duncan's use of anecdotes helps to de-mystify science and raises the readability level, such as when he relates being dared to taste a freshly regurgitated owl pellet in front of a crowd. He said it tasted "sweet," but his incredulous darer (R. W. Nero) bit into it and quickly spat it out, declaring that it tasted "bitter." They were both right $\ldots$ the pellet is coated with a $\mathrm{pH}$-neutral film of mucous that protects the owl's throat and mouth from the low-pH acid-soaked mass of fur and bones, which Nero had bitten into! 